\title{
Association between the X-ray repair cross-complementing group 1 Arg194Trp polymorphism and thyroid carcinoma susceptibility: A meta-analysis
}

\author{
J.Z. Zhao, X.R. Tan, M. Zhao, X.C. Mao and L. Jiang \\ Department of Head and Neck Surgery, Zhejiang Provincial Cancer Hospital, \\ Hangzhou, China
}

Corresponding author: X.R. Tan

E-mail: tanxiangrong01@sina.com

Genet. Mol. Res. 15 (3): gmr. 15037793

Received October 6, 2015

Accepted February 11, 2016

Published August 5, 2016

DOI http://dx.doi.org/10.4238/gmr.15037793

Copyright (C) 2016 The Authors. This is an open-access article distributed under the terms of the Creative Commons Attribution ShareAlike (CC BY-SA) 4.0 License

\begin{abstract}
Previous case-control studies having investigated the relationship between the X-ray repair cross-complementing group 1 (XRCC1) Arg194Trp polymorphism and thyroid cancer (TC) have drawn inconsistent conclusions. The current study aimed to clarify the role of this polymorphism in susceptibility to TC. An up-to-date search of PubMed and Web of Science databases was conducted, including articles published up to August 2015. Crude odds ratios (ORs) with $95 \% \mathrm{CIs}$ were calculated to establish the association between the XRCC1 Arg194Trp polymorphism and TC risk. Five studies were used, comprising 911 patients and 1476 controls. Our meta-analysis indicated that this polymorphism is associated with TC risk in Caucasians (TrpTrp vs ArgArg: OR $=5.72,95 \% \mathrm{CI}=1.39$ 23.54; ArgTrp vs ArgArg: OR $=1.20,95 \% \mathrm{CI}=0.87-1.66$; dominant
\end{abstract}


model: $\mathrm{OR}=1.31,95 \% \mathrm{CI}=0.96-1.79$; recessive model: $\mathrm{OR}=$ $0.18,95 \% \mathrm{CI}=0.04-0.73$ ). This investigation demonstrates that the XRCC1 Arg194Trp polymorphism constitutes a risk factor for TC in Caucasian individuals.

Key words: $X R C C 1$; Thyroid cancer; $\operatorname{Arg} 194 \operatorname{Trp}$

\section{INTRODUCTION}

Thyroid cancer (TC) is the most common endocrine malignancy and its global incidence has increased over recent decades (Jemal et al., 2011). TC is classified histologically into four major groups: papillary, follicular, medullary, and undifferentiated carcinomas. The mechanism behind thyroid carcinogenesis remains incompletely understood. To date, the only well-established etiological factor in the development of TC is exposure to ionizing radiation (Wang et al., 2013). However, only a small number of individuals exposed to radiation develop TC. This shows that genetic factors may play key roles in its pathogenesis. Recently, attention has focused on the impact of gene polymorphisms on TC, and many sequence variants have been put forward as risk factors, such as the C677T variation in the methylenetetrahydrofolate reductase gene (Yang et al., 2014).

DNA repair systems perform important roles in protecting cells against mutation, and are essential for maintaining genomic stability. To date, numerous proteins implicated in DNA repair have been found. Such proteins have been connected to four major DNA repair pathways in human cells, namely, nucleotide excision repair, base excision repair (BER), double-strand break repair, and mismatch repair (Wood et al., 2001). X-ray repair cross-complementing group 1 (XRCC1) is a major DNA repair protein in the BER pathway (Tudek, 2007). Loss of nuclear activity of this protein leads to decreased genome integrity, including an increased frequency of spontaneous and induced chromosome translocations and deletions (Rouse and Jackson, 2002).

The XRCC1 gene is located on chromosome 19 at q13.2-13.3, and is $33 \mathrm{~kb}$ in length, comprising 17 exons. The gene encodes a $70-\mathrm{kDa}$ protein consisting of 633 amino acids (Forat-Yazdi et al., 2015). Although numerous validated single nucleotide polymorphisms (SNPs) of this gene have been identified in the dbSNP database (http://www.ncbi.nlm.nih. gov/SNP), the Arg194Trp polymorphism has been the most researched of these XRCC1 variations, and is one of the most frequently studied of any DNA repair gene sequence variant (Custódio et al., 2011). This polymorphism may affect DNA repair by modifying interactions between XRCC1 and other proteins in the BER pathway, and many recent studies have payed close attention to its relationship with cancer pathogenesis (Tae et al., 2004; Wang et al., 2009).

Over the past decade, numerous epidemiological studies have assessed the association between the XRCC1 Arg194Trp polymorphism and TC risk. However, the results have been inconsistent. This may have been caused by small sample sizes, low statistical power, and/or clinical heterogeneity in these investigations. The aim of the present work was to assess the association between this polymorphism and TC susceptibility by performing a meta-analysis of all published case-control studies currently available in public databases.

Genetics and Molecular Research 15 (3): gmr.15037793 


\section{MATERIAL AND METHODS}

\section{Search strategy}

PubMed and Web of Science online databases were searched to retrieve papers published up to August 2015 having examined the connection between the XRCC1 Arg194Trp polymorphism and TC risk. The following keywords were used, with no language restrictions: "XRCC1", "Arg194Trp", "gene polymorphism", "thyroid cancer/ TC", and "single nucleotide polymorphism". This search was supplemented by manual research and a review of the reference lists included in retrieved articles. If necessary, attempts were made to contact the corresponding authors of retrieved articles to request additional information.

\section{Inclusion and exclusion criteria}

To be included in the meta-analysis, articles had to: 1) be case-control studies; 2) assess the association between the XRCC1 Arg194Trp polymorphism and TC risk; 3) provide sufficient information to estimate odds ratios (ORs) and their $95 \%$ confidence intervals (95\%CIs); and 4) provide data relating to Arg194Trp polymorphism genotype frequencies. The following were excluded: 1) reviews, editorials, or comments; 2) articles lacking genotype frequency data; and 3) duplicated studies.

\section{Data extraction}

Two reviewers (J.Z.Z. and X.R.T.) independently retrieved the following information from each included study: first author, year of publication, location, number of cases and controls, genotype frequencies in case and control groups, and evidence of Hardy-Weinberg equilibrium (HWE) in the control group. Differences of opinion between the two reviewers were resolved by discussion until an agreement was reached.

\section{Statistical analysis}

For data analysis, we used Stata software version 12.0 (StataCorp, College Station, TX, USA). HWE was assessed by the Fisher exact test, and $\mathrm{P}<0.05$ was considered to signify significant disequilibrium. The strength of association between the Arg194Trp polymorphism and susceptibility to TC was estimated by ORs and $95 \% \mathrm{CIs}$ using homozygote comparison (TrpTrp vs ArgArg), heterozygote comparison (ArgTrp vs ArgArg), and dominant (ArgTrp+TrpTrp vs ArgArg) and recessive (TrpTrp vs ArgArg+ArgTrp) models. Pooled effects were calculated using either the fixed- or random-effects model (Ding and $\mathrm{Li}$, 2015). The presence of heterogeneity was evaluated using the $I^{2}$ test. Data were considered to demonstrate significant heterogeneity when $I^{2}$ exceeded 50\%. Sensitivity analysis was performed by comparing random- and fixed-effects model estimates. Publication bias was assessed using a Begg's funnel plot, with $\mathrm{P}<0.05$ being considered to represent statistically significant bias.

Genetics and Molecular Research 15 (3): gmr.15037793 


\section{RESULTS}

\section{Study characteristics}

As a result of database searches, 33 papers were retrieved, of which five full-text articles were ultimately included in our meta-analysis (Chiang et al., 2008; Ho et al., 2009; Fard-Esfahani et al., 2011; Ryu et al., 2011; Santos et al., 2012). A flow chart representing the study selection process is shown in Figure 1. These five case-control studies included a total of 911 cases and 1476 healthy controls. Three of these investigations involved Caucasian participants (Ho et al., 2009; Fard-Esfahani et al., 2011; Santos et al., 2012), while two focused on Asian populations (Chiang et al., 2008; Ryu et al., 2011). The year of publication ranged from 2008 to 2014. Tests of genotype distributions in the control groups revealed no deviation from HWE. All studies were population-based, and in each case, controls were matched by sex and age to patients. All of the included investigations used a classical polymerase chain reaction-restriction fragment length polymorphism assay. Their main characteristics are listed in Table 1.

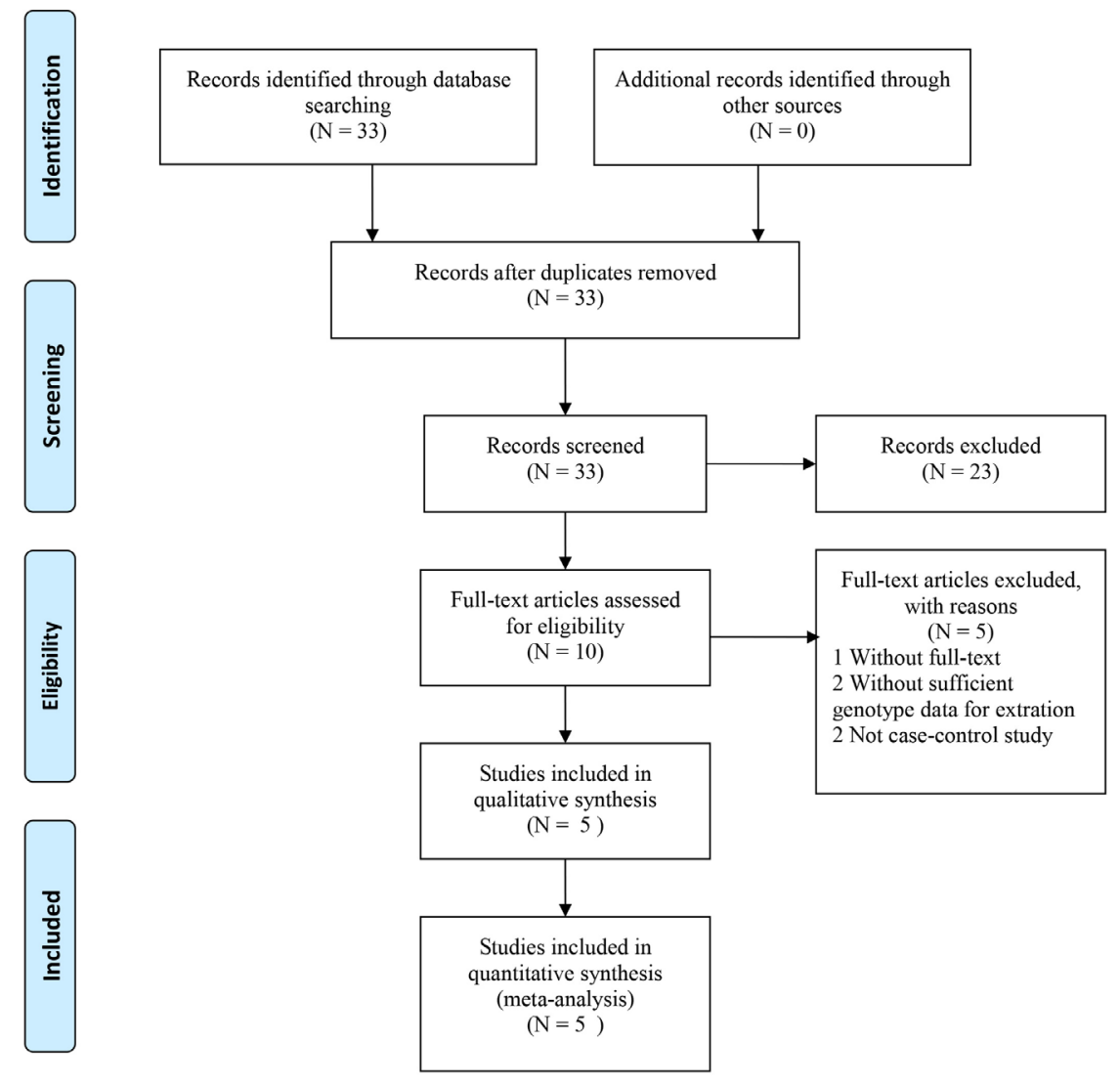

Figure 1. Flow chart showing the study selection procedure.

Genetics and Molecular Research 15 (3): gmr.15037793 
Table 1. Characteristics of the included studies for meta-analysis.

\begin{tabular}{l|l|l|l|c|c|c|c|c}
\hline Study & Year & Country & Ethnicity & Cases/controls & \multicolumn{2}{|c|}{ XRCCI Arg194Trp polymorphism (Cases/controls) } & HWE test \\
\cline { 6 - 8 } & & & & & Arg/Arg & Arg/Trp & Trp/Trp & \\
\hline Chiang et al. & 2008 & China & Asian & $283 / 489$ & $127 / 254$ & $119 / 199$ & $37 / 36$ & 0.73 \\
\hline Ho et al. & 2009 & USA & Caucasian & $251 / 503$ & $203 / 433$ & $45 / 69$ & $3 / 1$ & 0.31 \\
\hline Fard-Esfahani et al. & 2011 & Iran & Caucasian & $157 / 187$ & $136 / 166$ & $18 / 20$ & $3 / 1$ & 0.64 \\
\hline Ryu et al. & 2011 & Korea & Asian & $111 / 100$ & $59 / 37$ & $43 / 49$ & $9 / 14$ & 0.72 \\
\hline Santos et al. & 2012 & Portugal & Caucasian & $108 / 217$ & $98 / 196$ & $8 / 21$ & $2 / 0$ & 0.45 \\
\hline
\end{tabular}

HWE $=$ Hardy-Weinberg equilibrium.

\section{Meta-analysis results}

The results of our meta-analysis of the relationship between the XRCC1 gene Arg194Trp polymorphism and TC risk are summarized in Figures 2 and 3 and Table 2. This analysis identified no significant interaction between this polymorphism and susceptibility to TC (TrpTrp vs ArgArg: OR = 1.92, 95\% CI = 0.64-5.78; ArgTrp vs ArgArg: OR = 1.08, 95\%CI $=0.88-1.33$; dominant model: $\mathrm{OR}=1.07,95 \% \mathrm{CI}=0.75-1.54$; recessive model: $\mathrm{OR}=0.55$, $95 \% \mathrm{CI}=0.22-1.38)$.

In a subgroup analysis based on ethnicity, in which the data were divided into Asian and Caucasian subsets, a significant association was found between the Arg 194Trp polymorphism and TC risk among Caucasians (TrpTrp $v s$ ArgArg: OR $=5.72,95 \% \mathrm{CI}=1.39-23.54$; ArgTrp vs ArgArg: $\mathrm{OR}=1.20,95 \% \mathrm{CI}=0.87-1.66$; dominant model: $\mathrm{OR}=1.31,95 \% \mathrm{CI}=0.96-1.79$; recessive model: $\mathrm{OR}=0.18,95 \% \mathrm{CI}=0.04-0.73)$, but not Asians (TrpTrp vs ArgArg: OR $=0.96,95 \% \mathrm{CI}=0.19-4.71 ; \operatorname{Arg} \operatorname{Trp} v s$ ArgArg: $\mathrm{OR}=0.84,95 \% \mathrm{CI}=0.40-1.80$; dominant model: $\mathrm{OR}=0.85,95 \% \mathrm{CI}=0.34-2.15$; recessive model: $\mathrm{OR}=0.93,95 \% \mathrm{CI}=0.28-3.16$ ).

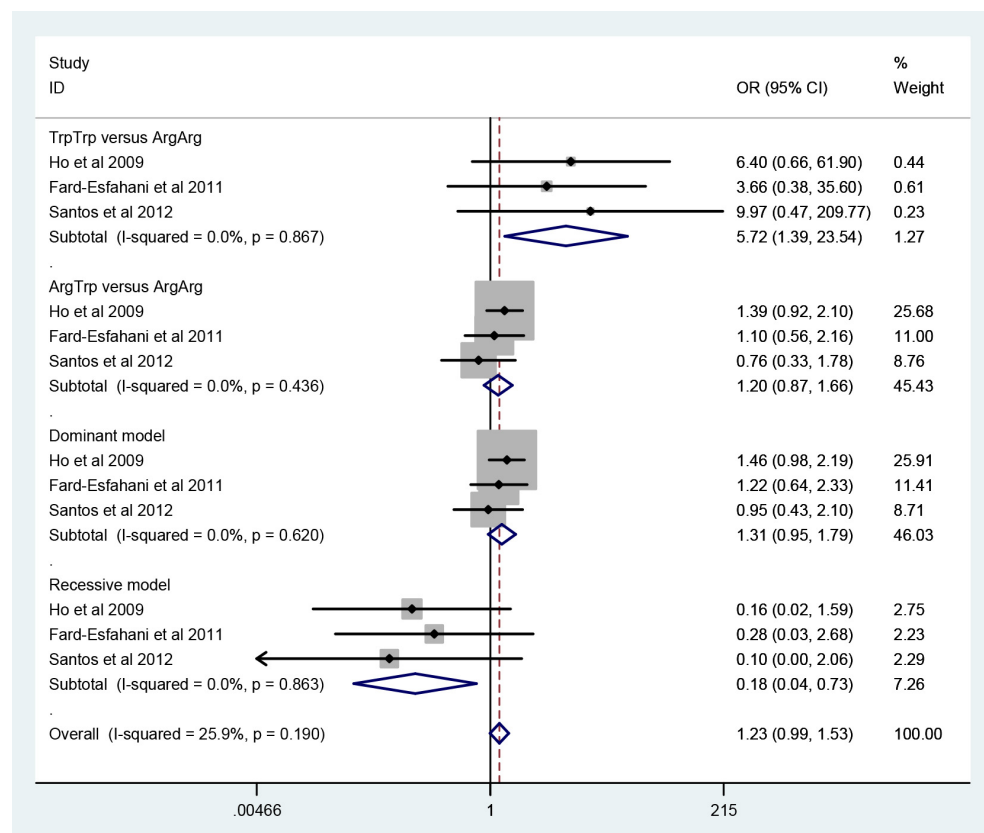

Figure 2. Forest plot assessing the association between thyroid cancer and the XRCC1 Arg194Trp polymorphism in Caucasian populations.

Genetics and Molecular Research 15 (3): gmr.15037793 


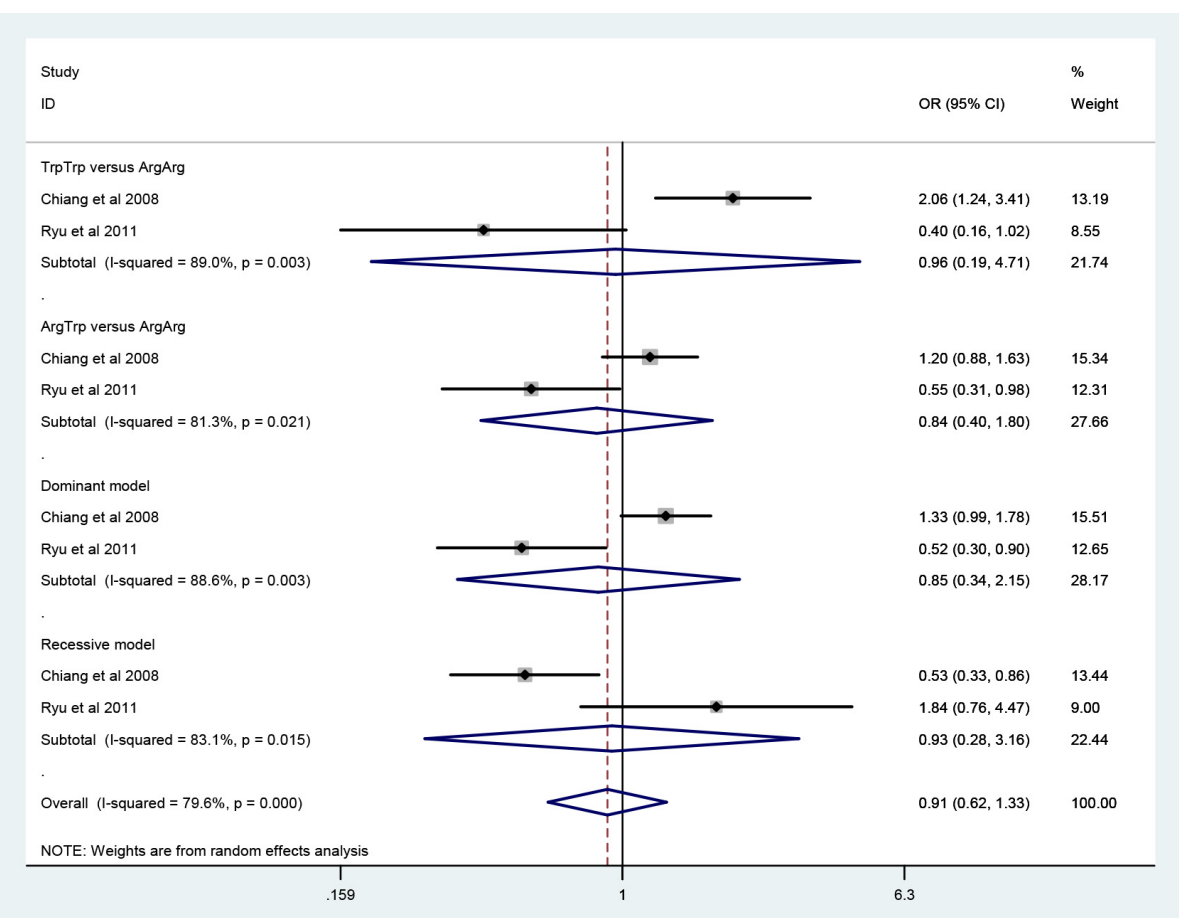

Figure 3. Forest plot assessing the association between thyroid cancer and the XRCC1 Arg194Trp polymorphism in Asian populations.

Table 2. Summary of odds ratios and $95 \%$ confidence intervals relating to the association between the XRCC1 Arg194Trp polymorphism and thyroid cancer risk.

\begin{tabular}{|c|c|c|c|c|c|c|c|c|}
\hline \multirow[t]{2}{*}{ Subgroup } & \multirow[t]{2}{*}{ Genetic model } & \multicolumn{2}{|c|}{ Sample size } & \multirow[t]{2}{*}{ Model } & \multicolumn{2}{|c|}{ Test of heterogeneity } & \multicolumn{2}{|c|}{ Test of association } \\
\hline & & Cases & Controls & & $I^{2}(\%)$ & $\mathrm{P}$ & OR & $95 \% \mathrm{CI}$ \\
\hline \multirow[t]{4}{*}{ Overall } & TrpTrp $v s$ ArgArg & \multirow[t]{4}{*}{911} & \multirow[t]{4}{*}{1476} & Random & 68.4 & 0.01 & 1.92 & $0.64-5.78$ \\
\hline & ArgTrp vs ArgArg & & & Fixed & 48.1 & 0.10 & 1.08 & $0.88-1.33$ \\
\hline & Dominant & & & Random & 62.2 & 0.03 & 1.07 & $0.75-1.54$ \\
\hline & Recessive & & & Random & 57.7 & 0.05 & 0.55 & $0.22-1.38$ \\
\hline \multirow{4}{*}{$\begin{array}{l}\text { Caucasian } \\
\mathrm{s}\end{array}$} & TrpTrp $v s$ ArgArg & \multirow[t]{4}{*}{517} & \multirow[t]{4}{*}{907} & Fixed & 0.0 & 0.87 & 5.72 & $1.39-23.54$ \\
\hline & ArgTrp vs ArgArg & & & Fixed & 0.0 & 0.44 & 1.20 & $0.87-1.66$ \\
\hline & Dominant & & & Fixed & 0.0 & 0.62 & 1.31 & $0.96-1.79$ \\
\hline & Recessive & & & Fixed & 0.0 & 0.86 & 0.18 & $0.04-0.73$ \\
\hline \multirow[t]{4}{*}{ Asians } & TrpTrp $v s$ ArgArg & \multirow[t]{4}{*}{394} & \multirow[t]{4}{*}{569} & Random & 89.0 & 0.00 & 0.96 & $0.19-4.71$ \\
\hline & ArgTrp $v s$ ArgArg & & & Random & 81.3 & 0.02 & 0.84 & $0.40-1.80$ \\
\hline & Dominant & & & Random & 88.6 & 0.00 & 0.85 & $0.34-2.15$ \\
\hline & Recessive & & & Random & 83.1 & 0.02 & 0.93 & $0.28-3.16$ \\
\hline
\end{tabular}

\section{Sensitivity analysis and publication bias}

Sensitivity analyses were performed by altering the statistical models. No single study was observed to substantially influence the pooled ORs. Therefore, the results of this metaanalysis were shown to be robust and credible. Visual inspection of the Begg's funnel plot generated for this analysis revealed no evidence of publication bias (Figure 4).

Genetics and Molecular Research 15 (3): gmr.15037793 


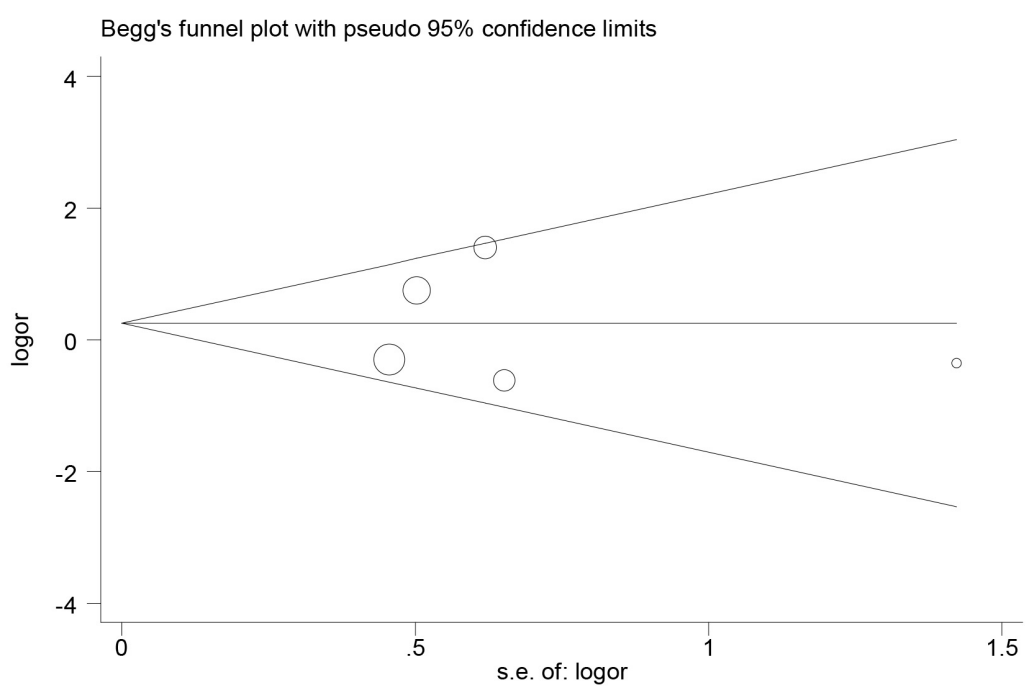

Figure 4. Begg's funnel plot as a test of publication bias.

\section{DISCUSSION}

Although TC currently accounts for less than $1 \%$ of human cancers, its incidence is increasing year after year. At present, the pathogenic mechanisms involved in the development and progression of TC are far from clear. Evidence is accumulating that this disease is a complex multifactorial disorder in which genetic factors play a key role. Genetic variations in genes controlling DNA repair and cell proliferation have an important influence on individual susceptibility to common cancers (Hunt et al., 2013). Previous studies of the interaction between the XRCC1 Arg194Trp polymorphism and TC risk have produced contradictory results. Meta-analysis is a method of increasing the effective sample size under investigation by pooling data from individual association studies, thus enhancing the statistical power to estimate genetic effects (Munafò and Flint, 2004). We conducted the present meta-analysis to explore the relationship between the XRCC1 gene Arg194Trp polymorphism and TC risk.

This meta-analysis included $911 \mathrm{TC}$ cases and 1476 controls. The results failed to establish a significant relationship between the polymorphism of interest and TC risk in the overall dataset. However, such analyses may be affected by differences in the ethnicities of study populations; hence, we performed a stratified analysis based on ethnicity. From this, we established the XRCC1 Arg194Trp polymorphism to be associated with TC risk among Caucasians, but not Asians. Three factors may explain this finding. First, the observed variation in the distribution of the Trp allele between Caucasians and Asians may be responsible for these contrasting results. Second, geographically separated populations tend to demonstrate different linkage disequilibrium patterns. A polymorphism may be in close linkage with another nearby causal polymorphism in one ethnic group, but not in another (Zhou et al., 2013). Third, other confounding factors, such as selection bias and different matching criteria, may also have caused this difference. In addition, as the number of studies included in this meta-analysis was limited, caution should be exercised when considering the conclusions reached. 
In interpreting the results of our meta-analysis, some limitations should be addressed. First, as only articles written in English were included, relevant studies published in other languages may have been overlooked. Second, as our meta-analysis involved only case-control studies, the patient groups necessarily consisted of living individuals, therefore those having died previously were not recorded. As a result, selection/survival bias could not be avoided to some extent. Finally, the influence of gene-gene and gene-environment interactions was not evaluated in our meta-analysis owing to lack of relevant data.

In conclusion, this study demonstrated that the XRCC1 Arg194Trp polymorphism is associated with TC risk in Caucasian populations. To achieve a more accurate conclusion, well-designed, unbiased, and large case-control studies should be performed.

\section{Conflicts of interest}

The authors declare no conflict of interest.

\section{REFERENCES}

Chiang FY, Wu CW, Hsiao PJ, Kuo WR, et al. (2008). Association between polymorphisms in DNA base excision repair genes XRCC1, APE1, and ADPRT and differentiated thyroid carcinoma. Clin. Cancer Res. 14: 5919-5924. http:// dx.doi.org/10.1158/1078-0432.CCR-08-0906

Custódio AC, Almeida LO, Pinto GR, Santos MJ, et al. (2011). Analysis of the polymorphisms XRCC1Arg194Trp and XRCC1Arg399Gln in gliomas. Genet. Mol. Res. 10: 1120-1129. http://dx.doi.org/10.4238/vol10-2gmr1125

Ding Y and Li LN (2015). Association between single nucleotide polymorphisms of X-ray repair cross-complementing protein 4 gene and development of pancreatic cancer. Genet. Mol. Res. 14: 9626-9632. http://dx.doi.org/10.4238/2015. August.14.25

Fard-Esfahani P, Fard-Esfahani A, Fayaz S, Ghanbarzadeh B, et al. (2011). Association of Arg194Trp, Arg280His and Arg399Gln polymorphisms in X-ray repair cross-complementing group 1 gene and risk of differentiated thyroid carcinoma in Iran. Iran. Biomed. J. 15: 73-78.

Forat-Yazdi M, Gholi-Nataj M, Neamatzadeh H, Nourbakhsh P, et al. (2015). Association of XRCC1 Arg399Gln polymorphism with colorectal cancer risk: a HuGE meta analysis of 35 studies. Asian Pac. J. Cancer Prev. 16: 32853291. http://dx.doi.org/10.7314/APJCP.2015.16.8.3285

Ho T, Li G, Lu J, Zhao C, et al. (2009). Association of XRCC1 polymorphisms and risk of differentiated thyroid carcinoma: a case-control analysis. Thyroid 19: 129-135. http://dx.doi.org/10.1089/thy.2008.0153

Hunt CR, Ramnarain D, Horikoshi N, Iyengar P, et al. (2013). Histone modifications and DNA double-strand break repair after exposure to ionizing radiations. Radiat. Res. 179: 383-392. http://dx.doi.org/10.1667/RR3308.2

Jemal A, Bray F, Center MM, Ferlay J, et al. (2011). Global cancer statistics. CA Cancer J. Clin. 61: 69-90. http://dx.doi. org/10.3322/caac.20107

Munafò MR and Flint J (2004). Meta-analysis of genetic association studies. Trends Genet. 20: 439-444. http://dx.doi. org/10.1016/j.tig.2004.06.014

Rouse J and Jackson SP (2002). Interfaces between the detection, signaling, and repair of DNA damage. Science 297: 547551. http://dx.doi.org/10.1126/science. 1074740

Ryu RA, Tae K, Min HJ, Jeong JH, et al. (2011). XRCC1 polymorphisms and risk of papillary thyroid carcinoma in a Korean sample. J. Korean Med. Sci. 26: 991-995. http://dx.doi.org/10.3346/jkms.2011.26.8.991

Santos LS, Branco SC, Silva SN, Azevedo AP, et al. (2012). Polymorphisms in base excision repair genes and thyroid cancer risk. Oncol. Rep. 28: 1859-1868.

Tae K, Lee HS, Park BJ, Park CW, et al. (2004). Association of DNA repair gene XRCC1 polymorphisms with head and neck cancer in Korean population. Int. J. Cancer 111: 805-808. http://dx.doi.org/10.1002/ijc.20338

Tudek B (2007). Base excision repair modulation as a risk factor for human cancers. Mol. Aspects Med. 28: 258-275. http://dx.doi.org/10.1016/j.mam.2007.05.003

Wang Y, Yang H, Li H, Li L, et al. (2009). Association between X-ray repair cross complementing group 1 codon 399 and 194 polymorphisms and lung cancer risk: a meta-analysis. Cancer Lett. 285: 134-140. http://dx.doi.org/10.1016/j. canlet.2009.05.005

Genetics and Molecular Research 15 (3): gmr.15037793 
Wang YL, Feng SH, Guo SC, Wei WJ, et al. (2013). Confirmation of papillary thyroid cancer susceptibility loci identified by genome-wide association studies of chromosomes 14q13, 9q22, 2q35 and 8p12 in a Chinese population. J. Med. Genet. 50: 689-695. http://dx.doi.org/10.1136/jmedgenet-2013-101687

Wood RD, Mitchell M, Sgouros J and Lindahl T (2001). Human DNA repair genes. Science 291: 1284-1289. http://dx.doi. org $/ 10.1126 /$ science. 1056154

Yang YM, Zhang TT, Yuan L and Ren Y (2014). The association between the C677T polymorphism in MTHFR gene and the risk of thyroid cancer: a meta-analysis. Eur. Rev. Med. Pharmacol. Sci. 18: 2097-2101.

Zhou B, Song Z, Qian M, Li L, et al. (2013). Functional polymorphisms in the CYP2C19 gene contribute to digestive system cancer risk: evidence from 11,042 subjects. PLoS One 8: e66865. http://dx.doi.org/10.1371/journal.pone.0066865

Genetics and Molecular Research 15 (3): gmr.15037793 